\title{
alphauille
}

\section{Cultural Innovation and Narrative Synergy in R. Kelly's Trapped in the Closet}

\author{
Ioana Literat, Annenberg School for Communication, University of Southern California
}

\begin{abstract}
This article analyses the narrative conventions of R. Kelly's serial "hip-hopera" Trapped in the Closet, exploring the manner in which the artist's chosen narrative strategies have shaped the generic reading of the series. Specifically, I discuss how Trapped in the Closet re-appropriates the conventions of the soap opera and the music video, to create a wholly original product that both evokes these schematas and simultaneously challenges their traditional narrative norms. Looking at R. Kelly's chosen promotional strategy, I argue that the convergence of genres and narrative influences, as evident in the series' content and style, parallels the convergence of media channels-radio, television, internet-that characterised its release and distribution, highlighting the increasing importance of a transmedial approach in the conceptualisation and dissemination of cultural texts.
\end{abstract}

"There are twists and turns that may make you think a certain way. But then, what you think is a twist may actually be a twang." R. Kelly on Trapped in the Closet (qtd. in Jones).

Self-proclaimed as the "king” (Kelly, "I'm a Flirt") and "Pied Piper of R\&B” (Kelly, "Step in the Name of Love"), Robert Sylvester Kelly, better known by his stage name R. Kelly, is a strange man and an even stranger artist. Unbruised by a myriad of scandals, including the child pornography charges for which he was acquitted in June 2008, R. Kelly's solo career in $\mathrm{R} \& \mathrm{~B}$ has spanned over fifteen years and has so far produced ten albums, all of which have gone platinum (Scaggs). His notorious ego is as much a part of his public persona as are his cornrows and classic cigar. "I'm the Ali of today. I'm the Marvin Gaye of today. I'm the Bob Marley of today", he recently told Hip-Hop Soul magazine. "I'm the Martin Luther King, or all the other greats that have come before us. And a lot of people are starting to realize that now" (qtd. in Frere-Jones).

In spite of the commercial success of his records, however, R. Kelly's tracks have met with mixed critical reviews, and The Washington Post is right in pinpointing the qualitative inconsistency of his work, suggesting that "his brilliance doesn't span entire albums, but rather pops up in the middle of his verses, as if by accident" (Richards). While his songwriting had always evidenced an intense authorial drive and enormous creative potential, it soon became clear that what R. Kelly needed was a more ambitious and cohesive project that would allow him to fully explore his creativity beyond the scope of tantalising R\&B singles and music videos. Trapped in the Closet (2005-present), a melodramatic musical saga in serial form described by the artist himself as a narrative "hip-hopera", was set to be his magnum opus. 
The extraordinary originality of Trapped in the Closet has set it apart from conventional musical and televisual products and, coupled with an extremely successful release strategy, has ensured an unforeseen success stretching far beyond his usual fan base and resulting in the series' quick propagation as a cult phenomenon. In this article I analyse the formal conventions of R. Kelly's perplexing serial hip-hopera, exploring how the artist's chosen narrative strategies have shaped both the production and the release of the series. The first part of the analysis examines the convergent release and distribution of Trapped in the Closet and discusses its popular and critical reception as a hybrid cultural product. The second part then theorises the ways in which R. Kelly reappropriates the conventions of the soap opera and the music video to create a wholly original form that both evokes these schemata and simultaneously challenges their narrative norms and aesthetics. Finally, I contend that the convergence of genres and narrative influences, as evident in the series' content and style, parallels the convergence of media channels (radio, television, internet) that characterised its release and distribution, highlighting the increasing importance of a "transmedial" approach (Herman 47) in the conceptualisation and dissemination of cultural texts.

\section{In the Beginning There Was the Song}

Trapped in the Closet seems, on one level, like an inevitable product of recent entertainment trends: the multimedia franchise, the automatic spinoff to DVD, the popularity of serial drama, the commercial success of R\&B (Ferguson). What really sealed its hit status, however, was its effective release strategy, which managed to capitalise on its unique adaptability to a variety of media, stirring curiosity and anticipation among viewers. Although he initially conceived it as an independent film, R. Kelly started by releasing the first five chapters on commercial radio, where, in spite of the songs' lack of a chorus or melodic hook, the intricate and suspenseful storyline immediately enticed viewers and kept radio station phones ringing. The beat of the songs, smooth but musically unimpressive, was maintained throughout all five chapters, and each episode picked up where the previous one had grippingly ended. Following the surprise popularity of the songs on the radio, Kelly went on to perform the premiere of Chapter 6, amidst heightened anticipation and roaring enthusiasm, at the 2005 MTV Music Awards.

If he had stopped here, Trapped in the Closet would still have been considered groundbreaking; however, the artist exceeded all expectations when he announced the release of the video version of the first twelve chapters in the saga, whose television premiere on BET was the top-rated show in the history of the channel (Wilson). Next, the series took the internet by storm, covering the entire spectrum of online video sites, from the very popular (YouTube, Veoh, DailyMotion) to the very high-end (The Independent Film Channel: ifc.com). Released in 2005, just as YouTube was taking off and the internet video revolution was underway, the duration and narrative structure of the chapters made the series highly suitable for online consumption, especially among its target audience of internet-savvy young viewers. Moreover, given its bizarreness and the word-of-mouth it generated, the series had an elusive aura that enticed the public; as one reviewer wrote in The New York Times, "it was the kind of pop 
spectacle you had to see to believe; thanks to the online video explosion, you could" (Sanneh). The series was also bought by The Independent Film Channel and released on the IFC website one chapter at a time, on a daily basis. Some considered this an unlikely move on the part of the IFC, a website which usually purchases films by the likes of Bernardo Bertolucci and Woody Allen and enjoys a strong reputation as an elite cinema forum. Nevertheless, the station's manager was quick to defend the Channel's decision. "Trapped in the Closet is a perfect example of an independent artist following his passion to create a unique work of art", he said. "I've never seen anything like it" (qtd. in Petridis). And the decision has certainly paid off from a financial perspective, as the number of unique visitors to the IFC website has increased three hundred per cent since the episodes premiered (Ryzik), while web advertising revenue was five hundred times greater than the previous year (Lafayette).

Moreover, repeat viewings are common, in spite of the series' dependence on suspense and narrative revelations; it has already acquired the status of a pop culture phenomenon, as evidenced by the many parodies and spoofs it has inspired on shows such as South Park, Saturday Night Live and Jimmy Kimmel Live. Private viewing parties have taken place across the U.S., along with sundry tribute performances and karaoke screenings. Comedians throughout the country have also found it profitable to mine the comedic potential of Trapped in the Closet. Aziz Ansari, for instance, has developed a commentary show about the series and has presented it in theatres in New York and Los Angeles, playing different characters and taking questions from the audience together with a panel of fellow comedians. Ansari acknowledges, however, that it is much harder than it looks to match Kelly's unique and particular style of humour: "We're merely racing his genius", he admits (qtd. in Ryzik).

In spite of Kelly's notorious and outspoken ego, the outstanding success of the series managed to bewilder even the artist himself. "I thought it was something different, but I had no idea it was going to explode like it did", he admitted. "Now it's taken on a life of its own. I've got it on a leash, and I'm going to walk it" (qtd. in Jones). And it looks like it will be a long and stupefying walk, as the singer has already revealed that he is planning to release more chapters and to turn Trapped in the Closet into a play and perhaps even a sitcom (Jones).

Trapped in the Closet is indeed such a visceral experience that it is nearly impossible to explain it to somebody who has never had the opportunity of seeing it. The plot revolves around the adventures of Sylvester, played by R. Kelly himself, who is involved in a web of adultery and deceit so intricate that it turns the classic love triangle into an entire romantic network. Sylvester is having an affair with Cathy (LeShay N. Tomlinson), the wife of the gay pastor Rufus (Rolando Boyce), who is romantically involved with Chuck (Malik Middleton). Sylvester's wife Gwendolyn (Cat Wilson) is also cheating on him with James (Michael Kenneth Williams), a policeman whose wife Bridget (Rebecca Field) is sleeping with a midget stripper called Big Man (Drevon Cooks). Together with Gwendolyn's brother Twan (Eric Lane), Sylvester must also take care of "business" involving debts, the Mafia and Twan's three-year old criminal conviction engineered by lesbian lovers Tina (Tracey Bonner) and Roxanne (Erika Ringor). In a testament to his authorial ambitions, R. Kelly plays the roles of Sylvester, the Narrator, Reverend Mosley from the church where Rufus works, Sylvester's septuagenarian neighbour Randolph and the stuttering Pimp Lucius, who is considering reforming his ways. 
The lyrics of the chapters contain the exact dialogue lines mouthed by the protagonists, word by word, as well as scenic indications and play-by-play descriptions of the action, such as "he says", "she yells", "he's opening the closet", "I pull out my Beretta" and so on. What is extraordinary - or extraordinarily peculiar - is that every single line is sung, dramatically, by R. Kelly himself, who emulates everything from female voices to Southern accents to guns going off to police sirens wailing, in the musical tempo and rhythm of his trademark R\&B crooning. The characters, who are extremely prone to both violence and emotional drama, are intertwined into a complex and mysterious web of relationships, and each chapter ends with a suspenseful cliffhanger that exposes further interconnections or makes more shocking revelations. These plot twists are so utterly absurd that they completely debunk any narrative expectations and norms of logical plausibility. In the words of comedian Aziz Ansari, from a narrative perspective, "most stories choose to make a right turn or a left turn. [R. Kelly] chooses to get into a space ship and fly to another planet" (qtd. in Ryzik).

The erratic nature of the series' narration mirrors the unpredictability of its plot. The story is told by Sylvester in first person narration until Chapter 8, when a mysterious omniscient narrator appears aurally in the episode cliffhanger: "But little does he [James] know / that somebody is still right there in his home!" In the next chapter, Chapter 9, the Narrator makes his first visual appearance as the cigar-smoking R. Kelly, who pops out of the closet and has the ability to freeze the action simply on the grounds that "what [he's] 'bout to tell y'all is so damn twisted..." As a result of the introduction of this onscreen extra-diegetic narrator-he visually appears within the setting, but the other characters cannot see him and he is not part of the storyworld itself-we can now see things Sylvester can't, but the implied distance imposed by the switch to third-person narration causes the story to lose intensity somewhat. After the narratively confused (and confusing) Chapter 9, in which R. Kelly's lyrics still oscillate between "I said" and "Sylvester said", the shift to third-person narration becomes permanent in Chapter 10 , and remains throughout the series (now numbering twenty-two released chapters with more in the offing).

In line with my previous argument about the genre amalgamation that characterises Trapped in the Closet and that has contributed to its innovation and exceptionality, the following sections will explore the various generic influences that have moulded R. Kelly's series, focusing primarily on the soap opera and the music video. Each section will consider, in turn, both the features that most significantly link it to the genre or art form under discussion and the conventions that differentiate it from the body of work that characterises each genre. I argue that, beyond the transmedial versatility of the series, a large part of its popular appeal and cultural innovation lies in the aesthetic and narrative convergence of these genre conventions.

\section{A Soap Opera}

With its serial format, narrative characteristics and domestic subject matter, Trapped in the Closet undoubtedly owes a debt to the conventions of the soap opera genre. Above all, it is the serialised nature of Trapped in the Closet that links it to the soap opera and its narrative 
strategy of delayed closure (itself rooted in serial radio drama). The cliffhangers at the end of each chapter of Trapped in the Closet - albeit substantially intensified in keeping with the narrative absurdity of the series - are typical of the kind of dramatic revelations or narrative twists at the end of soap opera episodes, and serve a similar dramatic function of stimulating viewers to watch the next instalment. Just as in soap operas, too, these cliffhangers often act as "miniclosures" within the larger context of the perpetually unresolved narrative (Mumford 71). For instance, the cliffhanger to Chapter 5 ("[Cathy] introduced me to the policeman that stopped you") solves the mystery surrounding the identity of Gwendolyn's lover, while the cliffhanger to Chapter 15 ("Because at the time, I was pregnant by you, T.") elucidates why Tina did not turn Twan in to the police.

Another narrative convention that links Trapped in the Closet to the genre of soap opera is its extensive cast and its focus on the relationships between this multitude of characters. Although Sylvester is arguably the central protagonist, the list of characters introduced throughout the chapters is long, especially given the short duration of the series in comparison to regular serial dramas. As in soap operas, the narrative is unabashedly concerned with the relationships between the characters and the act of deciphering these intricate links becomes one of the principal pleasures of watching R. Kelly's hip-hopera. Furthermore, Trapped in the Closet perfectly mirrors soap operas' obsession with the exchange of private information as a principal narrative drive. In both texts, a basic rule governing the storyworld is that "everything is everybody's business" (Mumford 40), and this violation of privacy is central to the progress of the narrative, as evidenced in the hip-hopera's reliance on gossip and token snoops like "Rosie the nosey neighbour".

Finally, another characteristic soap-opera feature of Trapped in the Closet is the ubiquitous melodramatic feel that percolates the narrative. This melodrama is reflected simultaneously in its subject matter (some of which-like adultery, jealousy and mysterious parentage - is typical soap opera material), its dramatic performances, and even in its mise-enscène, whose cheap backlighting and upper-middle class interiors automatically trigger the narrative schemata of the soap genre. Moreover, in the sense that melodrama uses music to underline emotional effects (Mumford 23), Trapped in the Closet, due to its continuous reliance on musical elements to convey drama throughout its narrative, can be considered the ultimate melodrama. Some musicologists claim that music, no matter the genre, holds an intrinsic narrative potential (Vernallis 19); in establishing such a direct link between music and narration, R. Kelly capitalises on this potential by efficiently placing music in the service of storytelling, while simultaneously ensuring that it does not divert attention from the developments onscreen.

\section{Not a Soap Opera}

Apart from reaching beyond a female-dominated target audience-which has interesting implications for the much-discussed connection between delayed closure and feminine subjectivity (Scodari 16; Nochimson 144) - the main quality that differentiates Trapped in the Closet from conventional soap operas is its scale. Both in terms of the number of episodes and the duration of each chapter, the narrative span of R. Kelly's opus is quite different from that of 
soap operas. Rather, the more limited episode span of Trapped in the Closet speaks to the dichotomy that Robert C. Allen identifies when comparing soap operas to the serialised fiction of Dickens or Collins (14). Like Dickens, R. Kelly might not have known, when he started writing the story, how the narrative would end, but his hip-hopera is envisioned as a finite series. By contrast, in soap operas, closure is delayed ad infinitum, and the purpose, according to Allen, is precisely that the story has no ending (13-14).

The very limited duration of each Trapped in the Closet chapter also challenges the soap opera convention of switching between different storylines within a single episode. Although the series maintains a focus on interlocking storylines and relationship webs, single chapters resemble scenes, rather than episodes, in soap operas. Each chapter tends to focus on a single storyline happening in a single setting and usually centred on the adventures and misdemeanours of its central protagonist, Sylvester. Moreover, brevity leaves little room for the redundancy characteristic of soap operas, which repeatedly recycle and retransmit past information for narrative purposes.

In terms of scheduling and distribution, R. Kelly's strategy of releasing the chapters in bundles - first five, then the next seven, and finally the last ten episodes he has written so farseparated by extensive hiatuses, differs substantially from the regular daily schedule of soapopera broadcasts. The most significant consequence of this atypical release strategy is that it prevents the series from becoming ritualistic viewing; soap operas cannot afford such long breaks, since the routine aspect of consumption, as well as the consequent sense of intimacy that results from viewers' daily exposure to the show, is a significant feature of the genre (Mumford 37).

And finally, quite unlike Trapped in the Closet, soap operas are dramatic texts par excellence and, though they may facilitate oppositional decodings, they generally take themselves and their conventions seriously. As Mumford puts it, "while soap opera performance may involve a high degree of self-consciousness and may even be overtly camp, the programs themselves are essentially unironic" (Mumford 32). Conversely, though the exact authorial intentions behind R. Kelly's hip-hopera are the subject of debate, it is clear that Trapped in the Closet is meant to provoke amusement and that it displays a high degree of ironic selfconsciousness in its narrative style. Jason Mittell argues that the narrative complexity and operational reflexivity that characterise many contemporary television shows are often manifested in the masterful interviewing of plot lines in unexpected, fateful ways. Part of the appeal of watching such shows, Mittell claims, is in "marvelling at the craft required to pull off such narrative pyrotechnics" (35), and I would argue that Trapped in the Closet, in its embrace of narrative complexity and self-consciousness, aligns itself with this generically innovative trend in contemporary American television.

\section{A Music Video}

Carol Vernallis suggests that, due to the fragmentary and non-cohesive nature of their narratives, music videos generally seem like "a miniature, a memento forever encased and out of 
reach in amber, a lively overpopulated flea circus forever locked under glass" (136). While Trapped in the Closet is indeed a kind of circus in its own respect, its ambitions far outstretch those of a conventional music video, and it therefore appears to be quite distinct from the genre parameters discussed by Vernallis and other theorists.

Upon first glance, a novice viewer unfamiliar with the serial nature of the show might be tempted to regard a single episode of Trapped in the Closet as a narrative-heavy music video: the duration of each chapter (five to six minutes) is suitable to the conventional length of a music video, the performer (R. Kelly) appears onscreen at the centre of the action, and song and image are correlated in a way that fully realises, and perhaps even exceeds, the "synaesthetic potential" that Kay Dickinson identifies in the cultural form of the music video (14). Moreover, from a commercial perspective, Trapped in the Closet perfectly fulfils one of the functions of a music video, in that it aims to entice viewers into buying the musical product that contains the songs: in this case, R. Kelly's album TP.3 Reloaded, which includes the first five chapters of the saga, as well as the two DVDs containing, respectively, Chapters 1-12 and 13-22). Roger Beebe's reading of contemporary music video offers other points of contact. Two major trends Beebe identifies - a gradual movement towards both auteurism and pastiche (313) - are key characteristics of R. Kelly's hip-hopera. So ingeniously does Trapped in the Closet embody and combine these features, in fact, that it could be seen as a potential model for success in the field of music video production.

\section{Not a Music Video}

Another significant feature that is likely to invoke comparison with music video is the saga's perpetual reliance on lip-synching as a central facet of its narrative aesthetic. Nevertheless, lip-synching in music videos conventionally occurs in the context of the performer directly addressing the audience, in a kind of reenactment of the concert experience (Vernallis 55); it is uncommon for lip-synching to occur as a dialogue between the characters within the video, as it does in Trapped in the Closet. The series most closely resembles a music video when R. Kelly stars as the Narrator, directly addressing the viewer while lip-synching the lyrics. Even in these moments, however, he does not stand in "temporal isolation", as Vernallis claims that performers in music videos usually do (54); rather, because of his onscreen presence in the midst of the action, he is perceived as clearly anchored in the narrative present - in spite of his external position in relation to the diegesis - and inseparable from the action he is recounting.

There are other features, too, that distance Trapped in the Closet from music video. According to Vernallis, most music videos tend to be non-narrative and to represent "a consideration of a topic rather than an enactment of it" (17). Vernallis identifies three principal reasons for this, none of which, I argue, apply meaningfully to R. Kelly's hip-hopera. First, Vernallis defines music video as a multimedia genre in which music, lyrics and image each foregrounds its "own language", combining and colliding in ways not conducive to the construction of narrative (13). In Trapped in the Closet, by contrast, the lyrics and the images are perfectly correlated (since the words describe both dialogue and actions in a perfect play-by-play commentary) while music assumes a less important role, rarely drawing attention to itself or 
foregrounding itself as medium. Second, Vernallis posits that the purpose of the music video is to call attention to the music - whether to enhance it or simply to sell it - and that intricate plots are avoided for fear that they might distract viewers (17). The relative demotion of music within the media economy of Trapped in the Closet hardly lends itself to this kind of music-centred function. And finally, Vernallis cites the absence in music videos of techniques familiar from narrative film devices: temporal constraints, she argues, mean that there is no time to develop a "narrative plank", and the demands of an "interesting present" take precedence over a "pressing future" (15). Kelly's series employs precisely the opposite strategy. Its serial form and duration allows for extensive plotting and a myriad of narrative devices. Moreover, its dependence on suspense emphasises the "pressing future" at the expense of the "interesting present".

The narrative of most music videos strives to follow the song's form, which tends to be cyclical and episodic, rather than "sequentially directed" (Vernallis 3). Edits are frequent, disjunctive or anti-naturalistic, and closely tied to the rhythm of the music. In Kelly's hip-hopera, however, the emphasis is on the narrative and the relationships between characters rather than on the music and so, as in soap opera, the edits are sparse and usually motivated by action and performance at the expense of rhythm. Moreover, the musical rhythm in the series is so constant and ritualised that calling attention to it by means of editing would do little to enhance the viewer's musical experience and might distract from the narrative.

As for the characters that populate the storyworld, roles and modes of address in music video tend to be inflexible: they must be established from the beginning and must remain stable throughout the video (Vernallis 57). Thus, while it is not uncommon for a performer to play both actor and narrator in the same music video, these roles have to be clearly set in place from the beginning and respected throughout. When R. Kelly establishes himself as a protagonist in Chapter 1, then later assumes the additional identity of onscreen narrator, he exceeds the narrative conventions of music video. Moreover, within the parameters of the genre, secondary characters are usually mute and demoted to a space and level of importance much inferior to that of the performer (Vernallis 64). In Trapped in the Closet they are a vital part of the narrative and even appear in scenes from which the performer (Kelly) is completely absent.

Finally, with regard to the function of lyrics in music videos, Vernallis argues that they are undoubtedly subservient to music and image: "they may almost become like film music, essential but often unheard and only sporadically capable of occupying the viewer's attention" (137). On the contrary, following the lyrics is arguably one of the chief pleasures of watching Trapped in the Closet, and paying attention to Kelly's words becomes indispensable to the comprehension of the intricate narrative they depict. It is entirely uncommon for the lyrics in a music video to be so directly correlated to the images on screen, almost erasing the distinction between lyrics and script; in this sense, there is a stronger resemblance to the conventions of sports commentary, where each move is narrated verbally in tandem with the development of the action onscreen. 


\section{Conclusion: Challenging Convention}

Since its debut in 2005, Trapped in the Closet has attracted an impressive number of fans, who eagerly await the next instalment of episodes. As an innovative cultural product that transgresses notions of good and bad taste, challenges genre conventions and benefits from a lively following, R. Kelly's series is a perfect exponent of a cult phenomenon (Mathijs and Mendik 11). Arguably, in this case, the subversion of conventional qualitative judgments has boosted the size and scope of the audience, drawing an unlikely fan base that stretches across the entire spectrum of the high/low-culture continuum. It is an audience that is able to derive enjoyment from the series regardless of - or perhaps even as a result of - the dichotomous ways it can be decoded qualitatively.

Trapped in the Closet poses a challenge to the scholar. Its enormous cultural impact seems to demand an awareness of its place within the larger cultural landscape, and it is now, when that awareness seems most available, that the research needs to be undertaken. But more than timely research, Trapped in the Closet demands an acceptance of novel impulses which challenge the conventional artistic hierarchy and its characteristic polarisation of the high and low ends of the cultural spectrum. Because when you do find that unique, original impulse, to borrow Mr. Kelly's distinctive metaphor, it's "just as you like cereal until you come to your favourite cereal and then you can appreciate cereal even more now, you know?" (qtd. in Flynn). And yes, I know, because that is exactly what Trapped in the Closet feels like.

\section{Works Cited}

Allen, Robert C. Speaking of Soap Operas. Chapel Hill: University of North Carolina Press, 1985. Print.

Beebe, Roger. "Paradoxes of Pastiche: Spike Jonze, Hype Williams, and the Race of the Postmodern Auteur". Medium Cool: Music Videos from Soundies to Cellphones. Ed. Jason Middleton and Roger Beebe. Durham: Duke University Press, 2007. 303-27. Print.

Dickinson, Kay. "Music Video and Synaesthetic Possibility". Medium Cool: Music Videos from Soundies to Cellphones. Ed. Jason Middleton and Roger Beebe. Durham: Duke University Press, 2007. 13-29. Print.

Ferguson, William. “The Serialized Pop Song”. The New York Times. 11 Dec. 2005. $<$ http://www.nytimes.com/2005/12/11/magazine/11ideas_section3-16.html?_r=1 > Web. 27 Oct. 2011.

Flynn, Paul. "Man in the Mirror: An Interview with R. Kelly". The Guardian. 19 Sept. 2004. $<$ http://www.guardian.co.uk/music/2004/sep/19/urban> Web. 27 Oct. 2011. 
Frere-Jones, Sasha. “Unbound: R. Kelly’s Latest Album”. The New Yorker. 2 July 2007. $<$ http://www.newyorker.com/arts/critics/musical/2007/07/02/070702crmu_music_frerejo nes?currentPage=all> Web. 27 Oct. 2011.

Gledhill, Christine. "Speculations on the Relationship between Soap Opera and Melodrama". Quarterly Review of Film and Video 14.1-2 (1992): 103-24. Print.

Herman, David. "Toward a Transmedial Narratology". Narrative across Media: The Languages of Storytelling. Ed. Marie-Laure Ryan. Lincoln: University of Nebraska Press, 2004. Print.

Jimmy Kimmel Live!. Prod. Jimmy Kimmel. ABC. WPLJ. New York City. 2003-present. Television.

Jones, Steve. "Cheatin' Hearts Let Go on Trapped". USA Today. 1 Nov. 2005. $<$ http://www.usatoday.com/life/music/news/2005-10-31-r-kelly_x.htm> Web. 20 Oct. 2011.

Kelly, R. "I'm a Flirt”. Double Up. Jive Records, 2007. MP3.

Kelly, R. "Step in the Name of Love (Remix)". Chocolate Factory. Jive Records, 2003. MP3.

Klosterman, Chuck. "Sex, Pies and Videotape". The Guardian. 25 Aug. 2007. $<$ http://www.guardian.co.uk/music/2007/aug/25/urban.dvdreviews> Web. 27 Oct. 2011.

Lafayette, Jon. "Hip-Hop Opera a Sensation for IFC". Television Week. 3 Sept. 2007. <http://www.highbeam.com/doc/1G1-168477519.html> Web. 27 Oct. 2011.

Mathijs, Ernest, and Xavier Mendik. "What Is Cult Film?". The Cult Film Reader. Ed. Ernest Mathijs and Xavier Mendik. New York: McGraw Hill, 2008. 1-12. Print.

Mittell, Jason. "Narrative Complexity in Contemporary American Television". The Velvet Light Trap 58.1 (2006): 29-40. Print.

Mumford, Laura S. Love and Ideology in the Afternoon: Soap Opera, Women, and Television Genre. Bloomington: Indiana University Press, 1995. Print.

Nochimson, Martha. No End to Her: Soap Opera and the Female Subject. Berkeley: University of California Press, 1993. Print.

Petridis, Alexis. "How Did R. Kelly Create the World's Strangest Soap Opera?" The Guardian. 19 Aug. 2007.

$<$ http://www.guardian.co.uk/music/musicblog/2007/aug/20/howdidrkellycreatethewor> Web. 27 Oct. 2011. 
Richards, Chris. "R. Kelly Doubles Up on Lusty Lyrics and Ego". The Washington Post. 29 May 2007. <http://www.washingtonpost.com/wpdyn/content/article/2007/05/28/AR2007052801517.html> Web. 27 Oct. 2011.

Ryzik, Melena. "R. Kelly's Killer Serial: Video, Music, Cliffhangers, Midgets". The New York Times. 16 Aug. 2007. <http://www.nytimes.com/2007/08/16/arts/music/16trap.html> Web. 27 Oct. 2011.

Sanneh, Kelefa. "Outrageous Farce From R. Kelly: He's In on the Joke, Right?". The New York Times. 20 Aug. 2007. <http://www.nytimes.com/2007/08/20/arts/music/20trap.html/> Web. 20 Oct. 2011.

Scaggs, Austin. "Q\&A: R. Kelly — Chi-town's R\&B King on 'Sex in the Kitchen' and Why the Right Ring Tone Still Doesn't Make You a Playa”. Rolling Stone, 24 Aug. 2005. $<$ http://archive.rollingstone.com/Desktop?s=2005082528\#/20050825/24> Web. 27 Oct. 2011.

Scodari, Christine. Serial Monogamy: Soap Opera, Lifespan, and the Gendered Politics of Fantasy. Cresskill, NJ: Hampton Press, Inc., 2004. Print.

Saturday Night Live. Prod. Lorne Michaels. NBC. WNBC. New York City. 1975-present. Television.

South Park. Creat. Trey Paker, Matt Stone. Comedy Central. New York City. 1997-present. Television.

Trapped in the Closet: Chapters 1-22. Dir. R. Kelly, Jim Swaffield, and Victor Mignatti. Jive Records, 2007. DVD.

Vernallis, Carol. Experiencing Music Video. New York: Columbia University Press, 2004. Print.

Wilson, Carl. "The Greatest Summer Single Ever”. The Globe and Mail. 16 July 2005. $<$ http://www.theglobeandmail.com/arts/the-greatest-summer-single-ever/article737671/> Web. 27 Oct. 2011.

\section{Suggested Citation}

Literat, Ioana. "Cultural Innovation and Narrative Synergy in R. Kelly's Trapped in the Closet". Alphaville: Journal of Film and Screen Media 3 (Summer 2012). Web. ISSN: 2009-4078. 
Ioana Literat is a doctoral student and Provost Fellow at the Annenberg School for Communication, University of Southern California. Advised by Dr Henry Jenkins, she is a researcher with PLAY! (Participatory Learning and You!) and the Public Interactives Research Team. Her research - which currently centres on crowdsourced art-examines participatory practices of collective creativity, as mediated by digital technologies. Ioana's professional background is in implementing digital storytelling curricula and media literacy campaigns in international contexts. 